\title{
ПРИМЕНЕНИЕ ЛАЗЕРНОЙ ЭМИССИОННОЙ СПЕКТРОМЕТРИИ (LIBS) ДЛЯ ИДЕНТИФИКАЦИИ МАТЕРИАЛОВ ВНУТРИ БАССЕЙНОВ ВЫДЕРЖКИ ОТРАБОТАННОГО ТОПЛИВА
}

\author{
А.Е. Чупров, ООО «Специальные Системы. Фотоника», info@sphotonics.ru, Санкm-Петербург, Россия
}

\begin{abstract}
Технология лазерной эмиссионной спектроскопии была впервые продемонстрирована в 1962 году на рубиновом лазере. Метод лазерной эмиссионной спектроскопии LIBS (Laser-Induced Breakdown Spectroscopy) заключается в том, что при облучении образца сфокусированным мощным короткоимпульсным лазерным излучением происходит испарение вещества, образуется плазма, эмиссионный спектр которой регистрируется спектральным прибором. По спектру излучения можно определить элементный состав исследуемого образца. Метод широко использовался в горнодобывающей и металлургической отраслях промышленности. Новые возможности в области лазерного эмиссионного анализа появились в связи с созданием волоконных лазеров и появлением многоэлементных оптических датчиков, что позволяет проводить дистанционно экспрессанализ химического состава образца. Представлено использование LIBS-метода в решении вопроса вывода из эксплуатации бассейнов выдержки отработанного ядерного топлива.
\end{abstract}

\section{ИСТОРИЯ ВОПРОСА}

Ядерное топливо, используемое в ядерных реакторах, помещается в герметично закрытых тепловыделяющих элементах (ТВЭЛ), которые объединены в тепловыделяющие сборки (ТВС). Использованное ядерное топливо содержит большое количество осколков деления урана и может саморазогреваться до больших температур. Поэтому отработанное ядерное топливо после выгрузки из активной зоны реактора помещают в специальный бассейн выдержки.

В бассейнах выдержки топливо хранится при определенном температурном режиме 3-4 года под слоем воды, защищающим персонал ядерных станций от ионизирующего излучения продуктов распада урана. По мере выдержки топлива в бассейне уменьшается его радиоактивность, саморазогрев ТВС сокращается с возможных $300{ }^{\circ} \mathrm{C}$ до $50-60{ }^{\circ} \mathrm{C}$. Далее топливо извлекают из бассейна выдержки и отправляют на захоронение или переработку. Однако на практике все оказывается сложнее.

Конструкция многих ранее спроектирован ${ }^{-}$ ных бассейнов выдержки отработанного ядерного топлива представляет собой открытый бассейн, который не защищен от атмосферной среды. В бассейн попадают внешние загрязнители, в том числе и переносимые по воздуху, например, солевые брызги (при локализации в прибрежных районах) или птичий помет. Из-за воздействия солнечного света открытые бассейны в значительной степени подвержены росту водорослей, что снижает под- водное видение до такой степени, что практически невозможно визуально идентифицировать подводные объекты [1]. В более современных конструкциях бассейнов выдержки ядерного топлива для минимизации попадание внешних загрязнений используют уже полностью закрытую конструкцию (рис. 1).

\section{ОПИСАНИЕ ПРОБЛЕМЫ}

Многие из бассейнов выдержки первых моделей в настоящее время являются избыточными и находятся на этапах вывода из эксплуатации. Но неко-

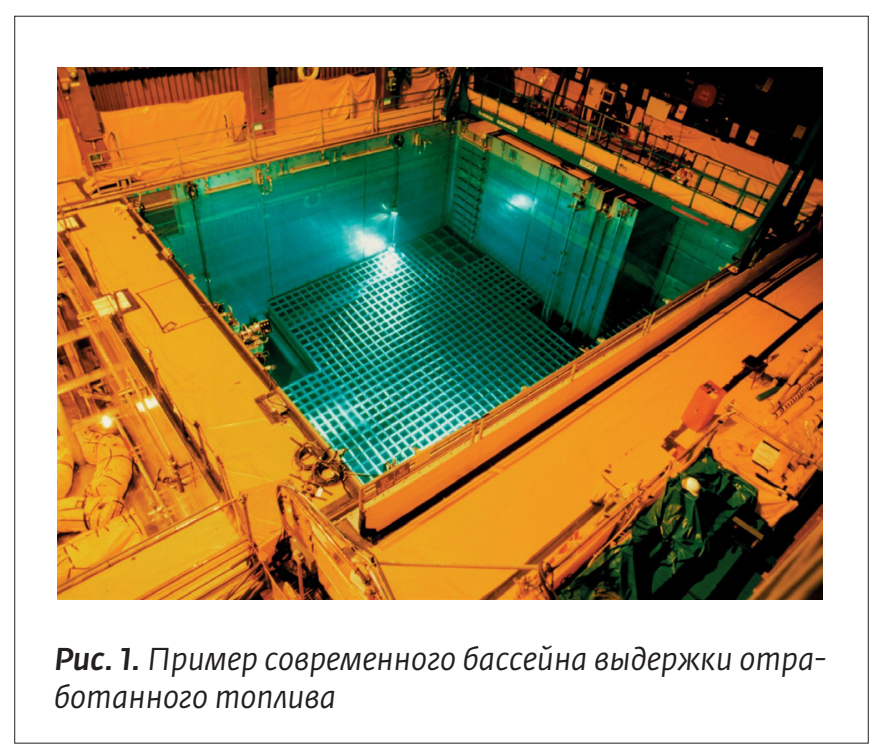




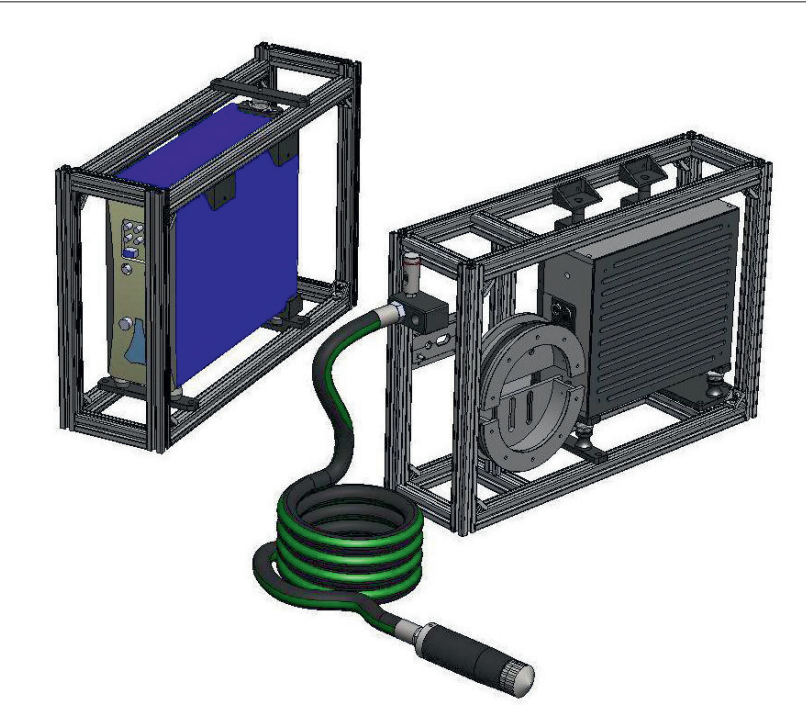

Puc. 2. Конструкция прибора: зонд LIBS и шиангокабель в cбope

торые из этих бассейнов продолжают использовать в качестве мест временного хранения радиоактивных отходов самого широкого спектра. Поэтому в настоящее время объектное содержание бассейнов неизвестно, в их подводном составе можно обнаружить смесь различных предметов, оборудования и материалов, включая и отработанное ядерное топливо. В дополнение к низкой видимости объектов в загрязненной из-за присутствия водорослей и других органических материалов воде в этих старых бассейнах вода часто сильно загрязнена радионуклидами из корродирующих ТВС в растворенном или взвешенном виде [1]. На этапе очистных работ по выводу бассейнов из эксплуатации необходимо охарактеризовать и идентифицировать компоненты и материалы, хранящиеся в бассейне еще до момента их извлечения,

Один из способов достижения этой цели - лабораторный анализ полученных физических образцов каждого компонента/материала. Извлечение материала из воды подвергает персонал воздействию ядерного излучения, а также может увеличить риск распространения загрязнения. Кроме того, физический отбор проб с последующим лабораторным анализом является очень трудоемким и, следовательно, дорогостоящим процессом. Определение характеристик компонента/материала во время его погружения (т.е. определение характеристик на месте эксплуатации) может дать существенные преимущества с точки зрения безопасности, скорости и общего снижения затрат.

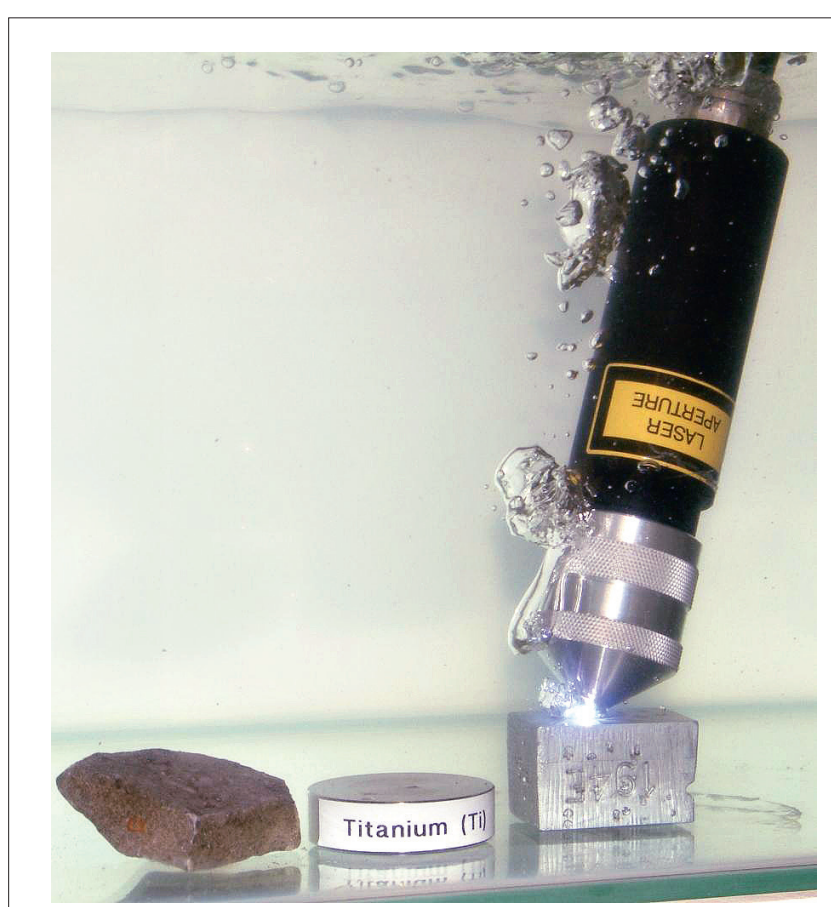

Puc. 3. Схема проведения анализа: инструмент LIBS анализирует материалы образцов, погруженных в воду

\section{LIBS-PЕШЕНИЕ}

Решить эти проблемы позволяет метод лазерной эмиссионной спектроскопии, который английская компания Applied Photonics Limited реализовала в выпускаемом продукте - LIBSProbe (рис. 2). Лазерный спектроанализатор [2] исполнен в виде волоконно-оптического кабеля и зонда LIBSProbe, имеющего возможность дистанционного погружения в водную среду (рис. 3) на любую глубину приблизительно до 10 метров. Зонд способен идентифици-

The LIBSProbe design successfully uses compact nanosecond Nd: YAG lasers from the Quantelby LUMIBIRD series. These are the ULTRA and CFR models in an airtight, dustproof, waterproof case with a power supply and cooling system in one portable, lightweight device ICE450. All laser systems that belong to the BSL series are tested for vibration resistance and heat resistance that meet the highest military standards for operation in the most unpretentious conditions (MIL-STD-810F).

Special Systems. Photonics LLC is the exclusive distributor of the company LUMIBIRD (France) and provides technical support for the entire LUMIBIRD product line in Russia and the Customs Union. You can get any additional information about LUMIBIRD products and technologies by contacting our specialists. 

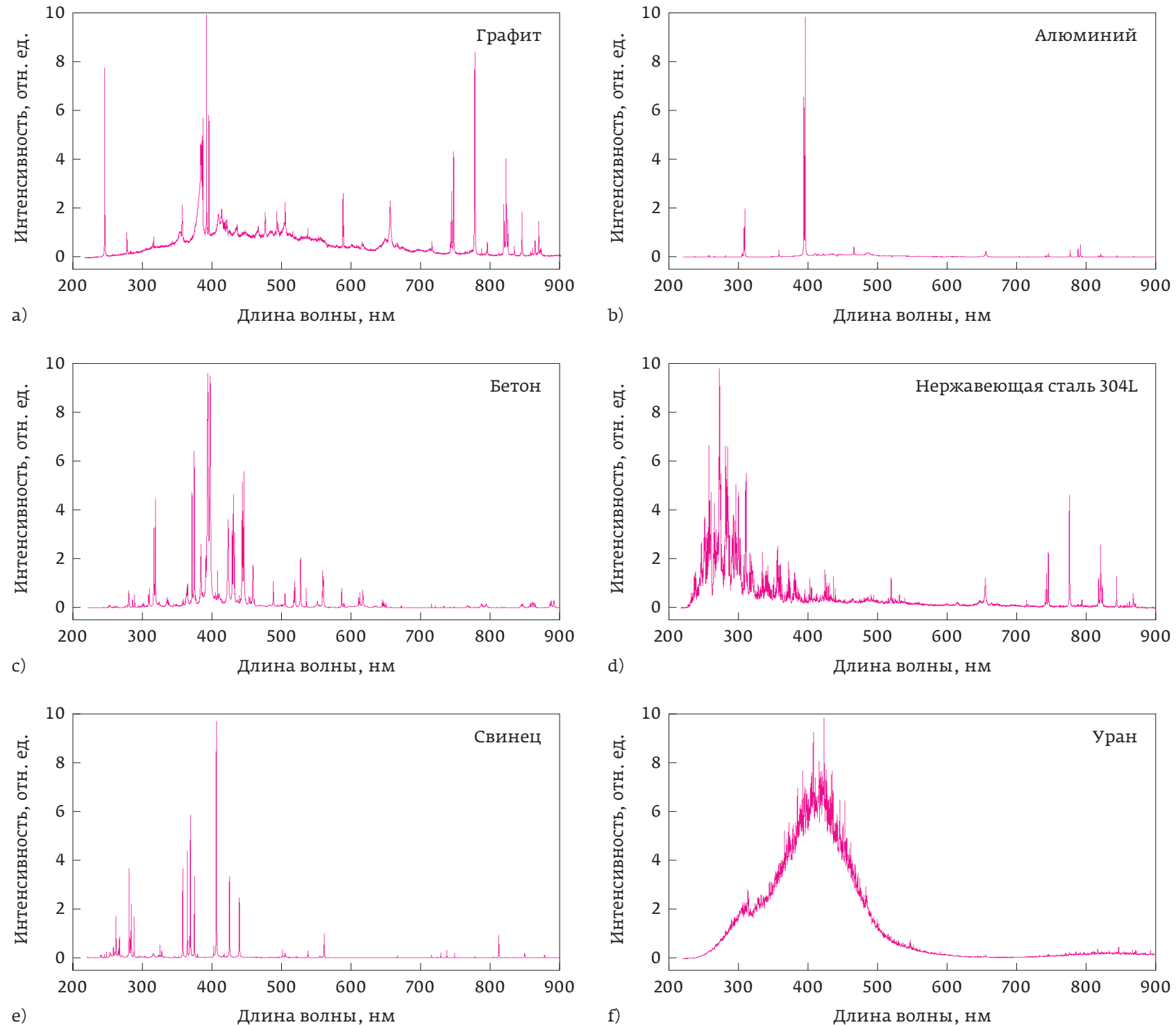

Puc. 4. (пектральные данные, полученные с помощью прибора LIBS: a) графит; b) алюминий; c) бетон; d) нержавеющая сталь 3041; е) свинец; f) уран

ровать элементный состав материалов и объектов, погруженных в воду. Из сопла зонда вперед выбрасывается небольшая струя газа (воздуха или аргона, что предпочтительней). Когда зонд контактирует с исследуемым компонентом, вода вытесняется потоком газа с оптического пути лазерного луча, что позволяет проводить лазерный эмиссионный спектральный анализ материала в газовой, а не в жидкой среде.

Достаточно только "неполного" уплотнения между зондом и компонентом - зонд не обязательно должен прилегать к поверхности материала и даже допускается зазор примерно до 2 мм. Поэтому дистанционное управление зондом значительно упрощается, поскольку не требуется точного позиционирования.
Небольшой поток газа, выходящий из сопла зонда, предотвращает попадание воды, даже когда зонд не контактирует с поверхностью материала.

С помощью этого прибора можно быстро и надежно идентифицировать различные материалы и их химический состав, в том числе уран, нержавеющую сталь, циркалоид, графит, алюминий, свинец и многие другие. Представленные необработанные спектральные данные (рис. 4) получены с помощью LIBSProbe. Данные иллюстрируют способность инструмента определять различные по химическому составу материалы. Анализ очень быстрый и во многих случаях может быть выполнен в считанные секунды. 


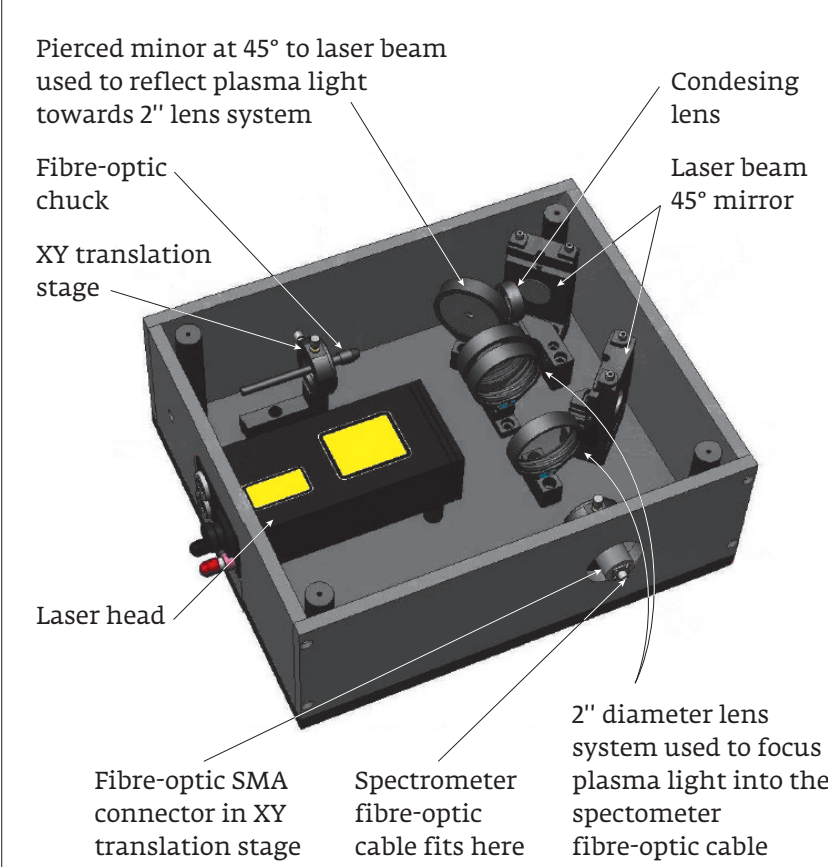

Puc. 5. Трехмерное изображение блока заведения пазерного излучения в оптическое волокно из CAD-редактора, в качестве излучателя - лазер ULTRA 100 (производство компании LUMIBIRD, Франция)

Конструкция LIBSProbe с успехом использует компактные наносекундные $\mathrm{Nd}: \mathrm{YAG}$-лазеры производства компании LUMIBIRD (Quantel Laser). Это модели ULTRA и CFR в герметичном пыле-влагозащищенном корпусе с блоком питания и системой охлаждения ICE450 в одном переносном, лег-

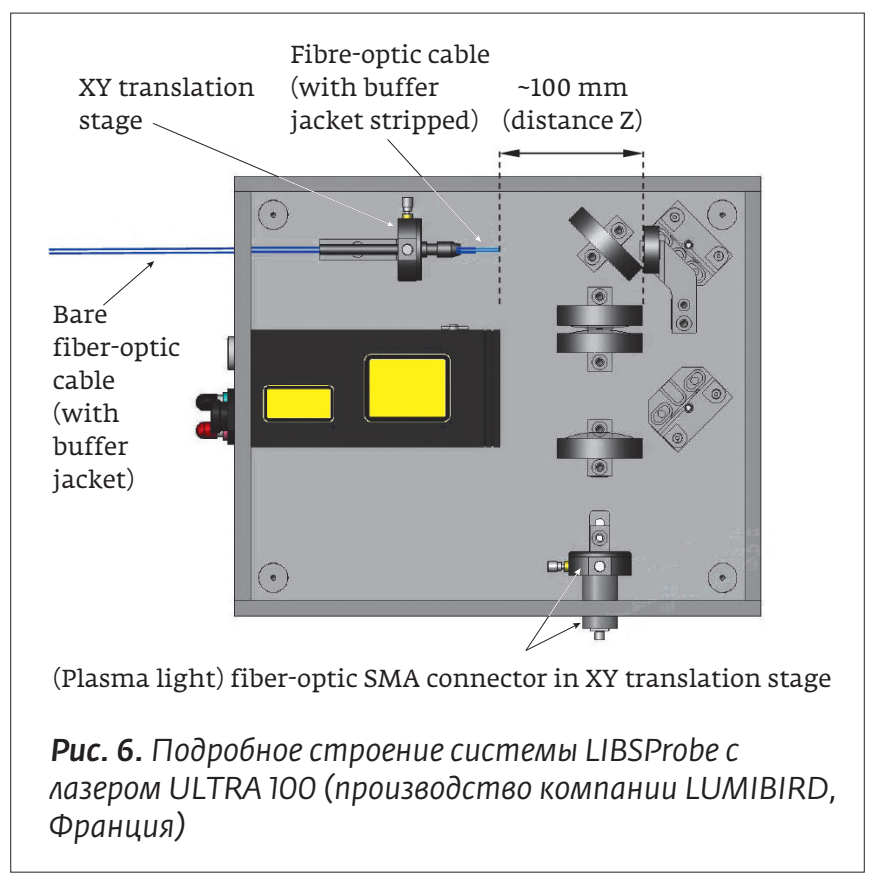

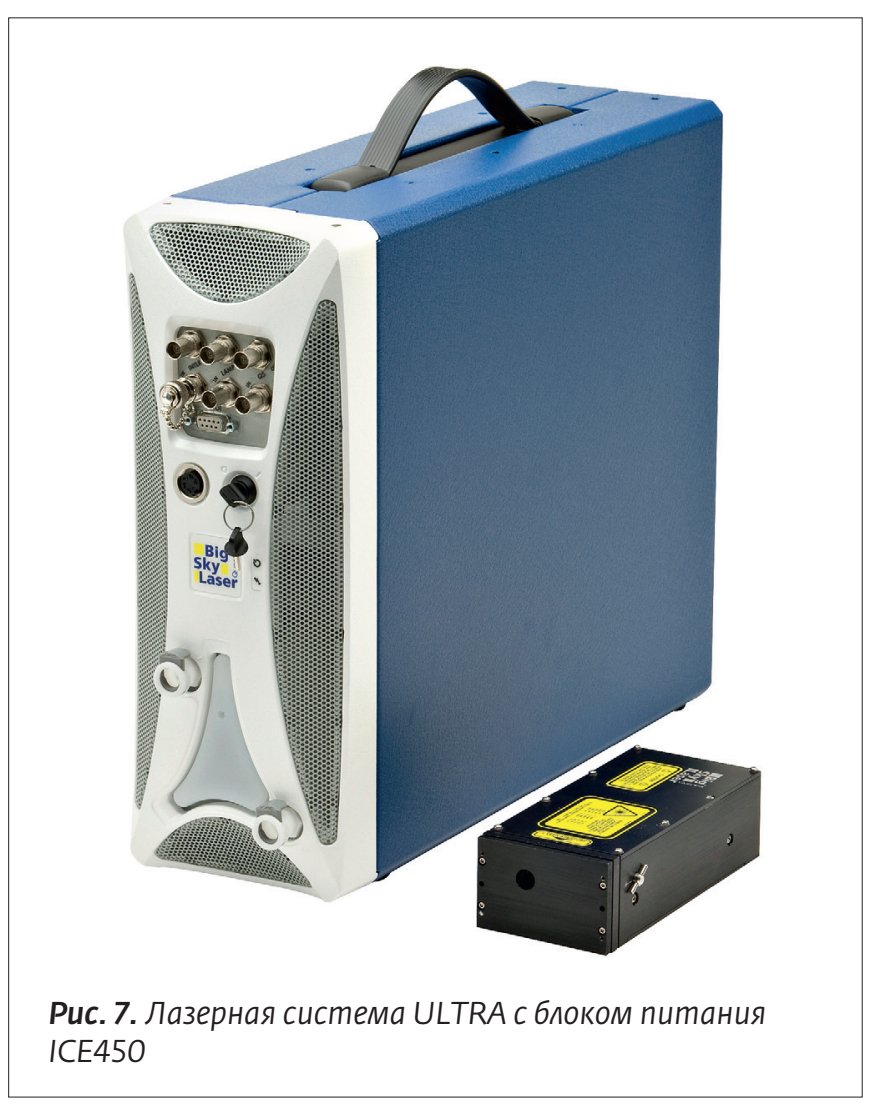

ком устройстве. Все лазерные системы, которые относятся к серии BSL, проходят испытания на виброустойчивость и теплостойкость, отвечающие высочайшим военным стандартам для эксплуатации в самых жестких условиях (MIL-STD-810F). Подробное строение всей системы LIBSProbe продемонстрировано на рис. 5 и рис. 6. На рис. 7. представлен внешний вид лазерной системы ULTRA вне прибора LIBSProbe.

\section{СПИСОК ЛИТЕРАТУРЫ}

1. Гордон Б. Интеграция SAFETY и SECURITY. ядерная физика и инжиринг. 2017; 8(3): 284-293. DOI: 10.1134/\$2079562917020099.

Gordon B. Integraciya SAFETY i SECURITY. YAdernaya fizika i inzhiring. 2017; 8(3): 284-293. DOI: $10.1134 / 52079562917020099$

2. URL [www.appliedphotonics. co.uk]

Компания "Специальные Системы. Фотоника" является эксклюзивным дистрибьютором компании LUMIBIRD (Франция) и оказывает техническую поддержку для всей линейной продукции LUMIBIRD на территории России и Таможенного Союза. Вы можете получить любую дополнительную информацию о продукции и технологиях LUMIBIRD, обратившись к специалистам нашей компании. 